\title{
Infancia y adolescencia en las noticias: representa- ción y tratamiento informativo de los menores de edad en la prensa diaria vasca
}

\author{
Miguel Ángel CASADO DEL Río \\ Universidad del País Vasco-UPV/EHU \\ miguelangel.casado@ehu.es \\ Estefanía JiMÉNEZ IGLESIAS \\ Universidad del País Vasco-UPV/EHU \\ estefania.jimenez@ehu.es \\ María Antonia MoReno CANO \\ Universidad del País Vasco-UPV/EHU \\ antonia_moreno@ehu.es
}

Recibido: $16 / 04 / 2012$

Aceptado: 30/10/2012

\begin{abstract}
Resumen
Las representaciones son modos de conocer y aproximarse a la realidad social e intentar comprenderla. La imagen de la infancia y la adolescencia recogida y amplificada por los medios de comunicación contribuye a configurar la opinión pública respecto a ese colectivo. La sociedad se relaciona con él a partir de la representación elaborada por los medios. Esta investigación analiza las piezas informativas y de opinión que aluden a niños, niñas y adolescentes aparecidas a lo largo de 2010 en la prensa diaria vasca, e identifica las áreas temáticas y el enfoque mayoritariamente empleado para informar al respecto.

Palabras clave: Adolescencia, estereotipo, framing, infancia, prensa

\section{Childhood and Adolescence on the News: Representation and Treatment of Minors on the Basque Press}

\begin{abstract}
Representations are ways to know and approach social reality and to equally understand it. The image given on the childhood and adolescence is gathered by media, and contributes to shape the public opinion on this collective. Is from this representation from where society acts and operates in relation to them. This research analyzes the pieces of news and opinion related to boys, girls and teenagers which appeared during 2010 on the Basque newspapers, and identifies which are the most common thematic areas and employed frames in order to inform on this group.
\end{abstract}

Keywords: Teenagers, stereotype, framing, childhood, newspaper.

\section{Referencia normalizada}

CASADO DEL RÍO, Miguel Ángel; JIMÉNEZ IGLESIAS, Estefanía; y MORENO CANO, María Antonia (2013): "Infancia y adolescencia en las noticias: representación y tratamiento informativo de los menores de edad en la prensa diaria vasca". Estudios sobre el mensaje periodístico. Vol. 19, Núm. 1, págs.: 53-69. Madrid, Servicio de Publicaciones de la Universidad Complutense.

Sumario: 1. Introducción. 2. Estado de la cuestión y objetivos de investigación. 3. Metodología. 4. Análisis; 4.1. Actividades dirigidas a menores; 4.2. Educación; 4.3. Infancia, familia y sociedad; 4.4. Menores como víctimas; 4.5. Menores con conductas; violentas; 4.6. Menores y nuevas tecnologías; 4.7. Menores y salud. 5. Conclusiones. 6. Referencias bibliográficas. 


\section{Introducción}

Las investigaciones centradas en el análisis de los contenidos transmitidos por los medios como elaboradores de discurso y reflejo de la representación social de un colectivo, han sido frecuentes. La difusión que realizan los medios sobre determinada visión de los hechos, particularmente en lo que concierne a los contenidos informativos, termina por ofrecer una representación de la realidad ajustada a los intereses de las audiencias:

"La noticia es una ventana al mundo [...] tiende a decirnos qué queremos saber, que necesitamos saber y qué deberíamos saber [...]. Pero, como todo marco que delinea un mundo, el marco de la noticia puede considerarse problemático. La visión a través de una ventana depende de si la ventana es grande o pequeña, si tiene muchos o pocos cristales, si el vidrio es opaco o claro, si la ventana da cara a una calle o a un patio. La escena que se despliega depende también de donde está uno, lejos o cerca, alargando el cuello hacia un costado o mirando recto hacia delante con los ojos paralelos a la pared en la que está colocada la ventana" (Tuchman, 1983: 13).

En este sentido, encuadrar o enmarcar un determinado tema, la infancia y la adolescencia en nuestro caso, pasa por "seleccionar algunos aspectos de una realidad percibida y darles más relevancia en un texto comunicativo" (Entman, 1993: 52). Se promueve así "una definición particular del problema, una interpretación causal del mismo, su evaluación moral, una recomendación de cómo debe ser tratado" (ibid.), entroncando con las premisas de las teorías de la agenda setting y el framing. De hecho, pese a ciertas dificultades para el desarrollo metodológico consensuado al respecto, durante las dos últimas décadas se puede percibir un constante aumento de estudios que recurren a los encuadres como herramientas conceptuales básicas para el análisis de contenido.

Tal y como indica Sádaba (2001), la teoría del framing conecta con uno de los eternos debates que atañen a los medios de comunicación: la posibilidad de transmitir la realidad tal como es, y al mismo tiempo, la imposibilidad de hacerlo y los múltiples elementos que explican esa dificultad: desde supuestos intereses editoriales a actitudes profesionales relacionadas con los procesos de socialización que se producen en las redacciones periodísticas y condicionan el modo en que los sucesos se convierten en productos informativos.

Igartua et al. $(2004,2006)$ recuerdan, además, que un mayor énfasis mediático sobre un determinado tema o asunto social tiende a provocar en la opinión pública una mayor preocupación sobre ese tema, lo cual dicta implícitamente una forma de pensar sobre ciertos asuntos. En este sentido, interesaba conocer las visiones de lo infantil y juvenil con las que los receptores conforman su universo referencial, que en ocasiones puede dirigir, orientar, valorar, juzgar u opinar sobre la realidad de los y las menores.

Como punto de partida, UNICEF se muestra muy crítica respecto al papel y el protagonismo que adquieren hoy en día los y las menores en nuestra sociedad. Según las conclusiones del informe La infancia en España 2010-2011 (Arias, Bello et al., 2010: 36) ésta "constituye el gran reto pendiente de la agenda social española. En España viven más de ocho millones de niños. Constituyen el 17,5\% de la población, están 
presentes en la publicidad, en los discursos y en los espacios de ocio, pero clamorosamente ausentes en los programas electorales, los presupuestos, los planes de acción y los boletines oficiales. Su protagonismo se diluye cuando pasamos del ámbito familiar al social, del plano emocional a la gestión pública".

\section{Estado de la cuestión y objetivos de investigación}

La percepción social respecto a los conceptos de infancia y adolescencia ha evolucionado considerablemente hasta llegar a la actualidad. Según Alzate (2001), los factores que intervienen en la configuración de la idea de infancia son diversos: los modos de organización socioeconómica de las sociedades, las formas o pautas de crianza, los intereses sociopolíticos, el desarrollo de las teorías pedagógicas, así como con el reconocimiento de los derechos de la infancia en las sociedades occidentales (García y Carranza, 1999). En última instancia, la infancia es "lo que cada sociedad, en un momento histórico dado, concibe y dice qué es la infancia" (Casas, 2006: 29).

La mayor parte de los trabajos que han abordado la relación entre menores y medios se centran más en la adolescencia que en la infancia. Un trabajo llevado a cabo por investigadores de la Universidad Complutense de Madrid para el INJUVE (Alcoceba, Matheus, 2010) analizó la imagen de los y las jóvenes tanto en prensa, como en radio y televisión, observando cómo entre los ámbitos temáticos en torno a los que se construye el universo mediático juvenil destacan los acontecimientos sobre hábitos de vida saludable -especialmente el denominado botellón y, en menor medida, toxicomanías, salud y tráfico-, y la respuesta institucional, predominante en los relatos, tiende a mostrar la estabilidad del mundo adulto frente a la irresponsabilidad e inestabilidad del mundo juvenil.

Asimismo, un estudio dirigido por el profesor Xavier Giró analizó en 2003 el tratamiento dado a los y las jóvenes en cuatro diarios catalanes en los que se contabilizaron un total de 452 piezas que proyectaban una imagen negativa del colectivo frente a 201 que reflejaban valores en positivo relacionados con jóvenes. Giró (2003: 123) subrayaba que la generalización de la imagen negativa no procedía tanto de generalizaciones gratuitas, sino de la proliferación de textos sobre jóvenes con carga valorativa negativa, especialmente relacionados con una violencia que casi nunca era explicada o contextualizada.

En otro estudio realizado sobre trece periódicos de calidad (Ponte, Bauwens et al., 2009; Garmendia, Garitaonandia et al., 2012) se observó cómo cerca del 70\% de las piezas publicadas sobre menores y nuevas tecnologías se referían a los riesgos asociados a internet y solo el restante $30 \%$ aludía a sus oportunidades para los menores, ahondando de ese modo en el discurso de los niños y niñas como sujetos pasivos y ciertamente indefensos a un entorno hostil en el que en muchas ocasiones, otros niños y niñas ejercían de victimarios.

Por su parte, el grupo de investigación sobre Infancias y Familias de la Universidad Autónoma de Barcelona (AFIN) respecto a la imagen de los y las menores en la prensa constató "la ausencia de los niños en sí mismos, así como su condición de imagen instrumental (...). Los escasos aunque bienintencionados discursos sobre agencia infantil existentes hasta el momento siguen siendo insuficientes, incluso por lo que 
constatamos a partir de su inexistencia en los medios de comunicación" (AFIN, 2009). Aidan White, Secretario General de la Federación Internacional de Periodistas, corrobora esta idea cuando dice que en los medios de comunicación "los niños suelen ser vistos y escuchados a distancia, lo que refleja su debilidad" y que "rara vez se permite a los menores hablar en su propio nombre" (White, 2002). Y llega a denunciar que cuando los derechos de la infancia ocupan un lugar destacado en los grandes medios de comunicación, "por lo general es en el contexto de abusos y explotación" (ibíd.)1.

Existen numerosos códigos y normativas que aluden a los derechos de los y las menores. De hecho, durante el siglo XX se dio una toma de conciencia al respecto que culminó con la aprobación, en 1959, de la Declaración Universal de los Derechos del Niño por la Asamblea General de las ONU. En España, la Convención sobre los Derechos del Niño entró en vigor en 1990, y jueces y magistrados han empleado esta norma como referencia a la hora de aplicar leyes y sustentar decisiones relacionadas con la protección y defensa de menores de edad. A su vez, han surgido organismos variados centrados en la defensa de los derechos de la infancia, defensorías de menores, ONGs y movimientos asociativos vinculados a este sector.

Además de este marco jurídico, y partiendo de que "el periodista es un intérprete de la realidad y eso exige un alto grado de responsabilidad en el ejercicio de su profesión" (Armentia, Caminos, 2009:21), la profesión periodística ha desarrollado diversos códigos deontológicos y éticos para el ejercicio de esta actividad, recogiendo normas y sugerencias para regular el comportamiento de los profesionales cuando informan sobre menores. Cabe mencionar la Guía para Periodistas y Profesionales de prensa (2002), Medios de comunicación y protección de la infancia en contexto de crisis humanitarias (2009) y el estudio Menores en los Medios de Comunicación encargado por el Defensor del Menor de la Comunidad de Madrid entre otras instituciones que concluye que:

"Los derechos al honor, la intimidad y la propia imagen del menor están suficientemente protegidas por nuestro ordenamiento jurídico. Sin embargo, los hechos demuestran que las leyes no son suficientes. Por eso es necesario insistir en la necesidad de la autocrítica y la autorregulación" (García, 2011:36).

Los medios son conscientes de que los contenidos que atañen a niños y niñas deben ser abordados con una especial atención. Prueba de ello es la preocupación mostrada por Milagros Pérez Oliva, la Defensora del Lector de El País al explicar los criterios utilizados por esta cabecera para el tratamiento de las imágenes de menores: margen de discrecionalidad y al rigor a la hora de pixelar las fotografías de niños que pudieran ser reconocidos en el ámbito de distribución del diario cuando se considere que la fotografía puede tener efectos negativos sobre el niño en caso de que sea reconocido,

1 Esta no es una crítica únicamente achacable al periodismo actual. Ya en los años ochenta la prensa española mostraba una abrumadora mayoría de piezas aludiendo a los niños como víctimas de actos violentos, accidentes, agresiones sexuales o malos tratos, frente a una minoría de piezas como protagonistas en positivo (Casas, 1998). 
para protegerlo de posibles daños a su imagen ${ }^{2}$. Otros medios también contemplan en sus respectivos libros o manuales de estilo ciertas recomendaciones relacionadas con el empleo de las fotografías de menores de edad.

No obstante, los códigos de actuación no tienen carácter legal ni obligatorio, y se limitan a establecer marcos de acción y referencia que, además, difícilmente van más allá de la preocupación por el tratamiento gráfico. No son coercitivos ni sistemáticos, ni de obligado cumplimiento. Y no se refieren a la selección y enfoque de los textos escritos cuando, en general, existen circunstancias condicionan la labor de los profesionales, como la falta de conocimiento al respecto, la escasez de recursos y precariedad, la urgencia o el sometimiento a la denominada tiranía de las audiencias, que puede conducir al sensacionalismo o a los enfoques estereotipados.

Teniendo en cuenta estas consideraciones, la presente investigación analiza la presencia y tratamiento de los y las menores en un contexto informativo concreto, el $\operatorname{vasco}^{3}$, a partir de los siguientes objetivos:

1. Cuantificar el número de informaciones periodísticas publicadas por la prensa vasca que tienen por objeto la realidad de los y las menores;

2. Identificar las principales áreas temáticas alrededor de las cuales giran esas informaciones y jerarquizarlas en función de su presencia y la importancia que le otorgan los medios de comunicación;

3. Determinar qué proporción de esas informaciones están protagonizadas por los propios menores y en cuáles la realidad infantil constituye un sujeto pasivo;

4. Analizar los encuadres periodísticos más reiterados al abordar la información referida a la infancia y la adolescencia.

\section{Metodología}

El trabajo de campo, de carácter hemerográfico, consistió en una recopilación y doble análisis cuantitativo y cualitativo de las informaciones aparecidas durante el año 2010 en la prensa vasca en las que estuvieran implicados menores, como protagonistas, fuentes principales o participantes de hechos noticiosos, y aquellas que abordaran cuestiones estructuralmente relacionadas con la infancia y la adolescencia. Se priorizó el análisis de la prensa escrita sobre el estudio de otros medios de comunicación por razones de practicidad, dado que se consideró más sencillo tanto recuperar las informaciones aparecidas como el análisis profundo y exhaustivo ${ }^{4}$.

2 El País 12/07/2010. A este respecto, en esa misma intervención Pérez Oliva también reconoce que la existencia de ediciones digitales ha trastornado ciertamente ese criterio, dado que la distribución de los diarios es ahora global, con lo cual niños fotografiados en lugares remotos podrían ser reconocidos también en esos entornos.

3 Según el Marco General de los medios en España 2012 (AIMC), el porcentaje de penetración de la prensa diaria en el País Vasco $(49,4 \%)$ es sustancialmente superior a la media española $(37,4 \%)$.

4 Si bien las conclusiones de este artículo se refieren en exclusiva al análisis de los textos escritos, el estudio también incluía un análisis minucioso de las fotografías que acompañaban a esas piezas, atendiendo al enfoque, encuadre, modo y contexto en el que niños y niñas eran retratados. 
Para definir el universo de estudio se tomaron en cuenta un total de seis diarios publicados en la Comunidad Autónoma Vasca y se siguió una técnica de semana compuesta para elegir una muestra representativa. Así, para todas las cabeceras, se tomó un lunes escogido al azar, y a partir de ahí se seleccionaron el martes de la semana siguiente, el miércoles de la siguiente y así sucesivamente los siete días de una semana $\mathrm{y}$, a su vez, las 52 semanas de un año.

La semana compuesta es una técnica de selección sobradamente probada y reconocida para el estudio de fenómenos, áreas o cuestiones generales cuya presencia mediática se alarga durante largos periodos de tiempo (Wimmer, Dominick, 1996), como es el caso de la representación de la infancia y la adolescencia. Igualmente, el análisis diacrónico a lo largo de 52 semanas garantiza una cierta cobertura de la realidad informativa sucedida a lo largo de todo el año ${ }^{5}$.

Las cabeceras analizadas fueron Deia, Diario Vasco, la edición vizcaína de El Correo Español, y las ediciones para el País Vasco de El Mundo y El País, que constituyen, según la OJD, las de mayor difusión en Euskadi'. A su vez, resultó oportuno incluir en el análisis al periódico Berria, el único diario editado íntegramente en euskera.

Cada una de estas cabeceras tiene características muy diferenciadas entre sí. Deia, Diario Vasco, y El Correo son medios de ámbito local en tanto que su difusión se restringe a un único territorio histórico: Bizkaia en los casos de Deia y El Correo, y Gipuzkoa en el de Diario Vasco. Berria se autodefine como de ámbito nacional, distribuyéndose y dirigiéndose al conjunto de la comunidad vascoparlante de Euskadi y Navarra. El Mundo y El País son medios de ámbito estatal que incluyen en su interior sendos cuadernillos elaborados por sus delegaciones autonómicas en Euskadi. En la muestra no se incluyeron suplementos especializados.

Todas las piezas pertinentes para el estudio fueron analizadas mediante una ficha diseñada ex profeso para recoger la información de carácter cuantitativo y cualitativo contenida en ellas. En cada ficha se tuvieron en cuenta la cabecera y la fecha de publicación; los elementos de titulación; el redactor o redactora que firmaban la pieza, o la agencia en su caso; el lugar en la que la información fue datada, distinguiendo entre las noticias ocurridas o referidas al País Vasco, el estado o el ámbito internacional; y el género al que estaba adscrita y la sección en la que fue publicada ${ }^{7}$. La ficha sometía a cada pieza a una escala de atención con el objeto de otorgar un valor cuantificable y comparable a cada noticia atendiendo a su ubicación y el espacio asignado, la presencia, en su caso, en la portada del periódico, el número de columnas, o el acompañamiento gráfico. Adaptando la escala de atención propuesta por Budd (1964), se asignó una pun-

5 En realidad se analizaron 51 periódicos por medio, dado que el 3 de abril de 2010, inicialmente previsto en la muestra, correspondió al sábado de Semana Santa, jornada en la que no se publicó prensa.

6 Datos de difusión en 2009 según la OJD: El Correo (79.120); El Diario Vasco (70.409); Deia (17.328); El País (5.870); El Mundo (5.542).

7 Aunque la distribución por secciones es diferente para cada cabecera, es posible trazar ciertas equivalencias, como por ejemplo Mundo e Internacional. Según ellas, las denominaciones equivalentes se equipararon para uniformizar el análisis. 
tuación diferente a cada información analizada que permitía considerar a éstas desde muy poco interesantes hasta acreedoras de un interés máximo (tabla 1).

Tabla 1. Ficha de medición de la escala de atención (fuente: elaboración propia)

\begin{tabular}{|l|l|r|}
\hline \multirow{4}{*}{ 1. Portada } & Noticia de apertura & 1.00 \\
\cline { 2 - 3 } & Fotonoticia & 0.75 \\
\cline { 2 - 3 } & Noticia de no apertura & 0.50 \\
\cline { 2 - 3 } & Llamada & 0.25 \\
\hline 2. Apertura de sección o cintillo & & 0.75 \\
\hline 3. Página impar & & 0.25 \\
\hline \multirow{4}{*}{ 4. Columnas } & Cinco columnas & 4.50 \\
\cline { 2 - 3 } & Cuatro columnas & 4.00 \\
\cline { 2 - 3 } & Tres columnas & 3.00 \\
\cline { 2 - 3 } & Dos columnas & 2.00 \\
\cline { 2 - 3 } & Una columna & 1.50 \\
\hline 5. Mitad superior & & 0.50 \\
\hline 6. Más de media página & & 0.50 \\
\hline \multirow{2}{*}{ 7. Acompañamiento gráfico } & Infográfico & 0.50 \\
\cline { 2 - 3 } & Fotografía & 0.25 \\
\hline Máxima puntuación obtenible & & 8.25 \\
\hline
\end{tabular}

En la ficha de análisis también se tomó en consideración el género de los menores aludidos en las informaciones -niñas, niños, ambos, o indeterminado-, y la franja de edad en la que situarlos -de 0 a 5 años, Educación Infantil; de 6 a 11 años, Educación Primaria; y de 12 a 15 años, Educación Secundaria-.

Para testar la ficha se efectuó un análisis preliminar de las piezas susceptibles de análisis publicadas durante enero, a partir del cual se identificaron ocho temas diferenciados para clasificarlas. Dada la amplitud de estas temáticas, y buscando un análisis de segundo nivel, también se propusieron diferentes subtemas bajo los temas principales. Así, se distinguieron ocho temas y 42 subtemas, de acuerdo a esta distribución: (1) actividades protagonizadas o dirigidas a los menores -culturales/educativas; deportivas; ocio/festivas; otros-; (2) educación -conflictos laborales; educación y religión; Eskola 2.0 $0^{8}$; euskera; evaluación del sistema educativo/alumnado; sistema educativo; Plan de Educación para la Paz; política lingüística en educación; otros-; (3) infancia, familia y sociedad -adopción y acogida; asistencia y cuidado de menores; conductas violentas en la familia; separación y tutela; reparto de tareas y conciliación laboral; otros-; (4) menores como víctimas -abuso sexual; abuso sexual en la familia; abuso sexual en la Iglesia; accidentes; desaparición y robo de menores; guerras/desastres naturales; pobreza/desprotección; violencia en el hogar; otros-; (5) menores con conductas violentas -bandas de delincuentes; casos de agresión; conductas violentas en la familia; otros-; (6) menores y nuevas tecnologías -ciberacoso/ciberbull-

8 Programa del Gobierno Vasco para la implantación de las nuevas tecnologías en el sistema educativo. 
ying; educación; uso seguro; otros-; (7) menores y salud -alimentación; atención sanitaria; general; tabaco, alcohol y drogas; otros-; y (8) otros, que no pudieron incluirse en ninguno de los apartados ya expuestos.

\section{Análisis}

Se contabilizaron 844 piezas informativas, cuya distribución homogénea a lo largo de todo el año invita a deducir que la infancia es un concepto muy presente en la agenda de los medios, en los que aparece representada de manera constante. Las piezas informativas relacionadas con la educación o las políticas educativas fueron las más numerosas: suponen el $27 \%$ de las noticias que forman parte de la muestra. De forma igualmente destacada encontramos temáticas en las que niños o niñas aparecen como víctimas $(20 \%)$, considerando esta idea en un sentido amplio. Las piezas sobre actividades protagonizadas o dirigidas a menores también ocupan un lugar importante sobre el conjunto de las analizadas (19\%), y aquellos temas que tienen que ver en general con la infancia, la familia y la sociedad representan el $11 \%$ del total. En menor medida, aparecen aquellas noticias que hablan de la salud de menores o de otros temas, suponiendo ambos apartados el $8 \%$ del conjunto de las piezas analizadas. Las piezas relacionadas con menores con conductas violentas son las que transmiten un reflejo más negativo de la imagen de los menores, y sólo constituyen el 3\% de los casos. Las piezas que relacionan a la infancia con las nuevas tecnologías suponen un $2 \%$ del total.

El análisis de la procedencia geográfica de las noticias señala que los medios analizados dan prioridad periodística a aquellas que ocurren dentro de la Comunidad Autónoma Vasca, ya que éstas representan más de la mitad del total de las piezas informativas identificadas (56\%). Mientras, sólo en el 25\% de las informaciones procesadas corresponden al ámbito estatal. Las informaciones que se generan a nivel internacional suponen el 19\% restante. A este respecto, es destacable la constatación de que la mayor parte de las piezas sobre educación y actividades dirigidas a menores se refieren a noticias de la $\mathrm{CAV}$, mientras que aquellas que muestran a los menores como víctimas son, en su mayoría, piezas de ámbito internacional o estatal (tabla 2).

Tabla 2. Clasificación de las piezas analizadas por tema y ámbito geográfico (fuente: elaboración propia)

\begin{tabular}{|l|r|r|r|r|r|r|r|}
\hline \multirow{2}{*}{ Tema } & \multicolumn{6}{|c|}{ Ámbito geográfico } & \multirow{2}{*}{ Total general } \\
\cline { 2 - 6 } & \multicolumn{2}{|c|}{ CAV } & \multicolumn{2}{|c|}{ Estado } & \multicolumn{1}{|c|}{ Internacional } & \\
\hline $\begin{array}{l}\text { Actividades protagonizadas o di- } \\
\text { rigidas a los menores }\end{array}$ & 142 & $89,9 \%$ & 5 & $3,2 \%$ & 11 & $7,0 \%$ & $19 \%(158)$ \\
\hline Educación & 161 & $70,9 \%$ & 54 & $23,8 \%$ & 12 & $5,3 \%$ & $27 \%(227)$ \\
\hline Infancia, familia y sociedad & 44 & $47,8 \%$ & 24 & $26,1 \%$ & 24 & $26,1 \%$ & $11 \%(92)$ \\
\hline Menores como víctimas & 30 & $17,8 \%$ & 64 & $37,9 \%$ & 75 & $44,4 \%$ & $20 \%(169)$ \\
\hline Menores con conductas violentas & 10 & $35,7 \%$ & 14 & $50,0 \%$ & 4 & $14,3 \%$ & $3 \%(28)$ \\
\hline Menores y nuevas tecnologías & 11 & $61,1 \%$ & 7 & $38,9 \%$ & 0 & $0,0 \%$ & $2 \%(18)$ \\
\hline Menores y salud & 39 & $59,1 \%$ & 17 & $25,8 \%$ & 10 & $15,2 \%$ & $8 \%(66)$ \\
\hline Otros & 40 & $46,5 \%$ & 22 & $25,6 \%$ & 24 & $27,9 \%$ & $8 \%(86)$ \\
\hline Total general & 477 & $56,5 \%$ & 207 & $24,5 \%$ & 160 & $19,0 \%$ & $100 \%(844)$ \\
\hline
\end{tabular}


Respecto al género del o la menor protagonista de las piezas analizadas, en la mayoría de las ocasiones las noticias y comentarios se refieren a ambos sexos (76\%), y en menor medida se hace referencia a menores concretos especificando si son niños $(13 \%)$ o niñas (11\%). Dado que la mayoría de piezas aluden a aspectos generales sobre la infancia o a políticas vinculadas al sector, como por ejemplo la educación, hay muchas ocasiones en las que no se hace referencia a menores en concreto. Las piezas en las que sí son identificados de modo expreso suelen referirse a actividades realizadas por ellos o a situación en las que son víctimas de un suceso concreto.

La edad de los o las menores aludidos confirma que, en un porcentaje elevado, este dato resulta importante para los medios, que suelen explicitarlo en las informaciones $(61 \%)$. Entre las piezas que especifican la edad concreta se nombra en el mismo porcentaje (13\%) tanto a los niños o niñas más pequeños, de entre 0 y 5 años, como a los más mayores de entre 12 a 15, convertidos en su transición hacía la juventud en sujetos generadores de noticias. El 26\% del total de informaciones se refieren de manera expresa varios menores -protagonistas o sujetos pasivos- de edades distintas entre sí.

La escala de atención aplicada para analizar la atención prestada a cada una de las piezas permite observar que más de la mitad de ellas tienen una relevancia muy alta o máxima (tabla 1). Es especialmente llamativa la presencia de piezas de interés alto o máximo en el caso de las noticias sobre menores y salud o los casos de menores con conductas violentas. Son muy pocas las informaciones analizadas de relevancia baja o muy baja.

\subsection{Actividades dirigidas a menores}

Una de cada cinco piezas analizadas alude a distintos tipos de actos, actividades o acontecimientos organizados por o para ellos (19\%, 158 piezas), dentro de las cuales se consideran iniciativas culturales o educativas -que copan casi la mitad de las piezas analizadas-, actividades deportivas, actividades relacionadas con el ocio y las fiestas, $\mathrm{u}$ otro tipo de actividades pensadas para los y las menores.

Aun no siendo todas, muchas de las informaciones que hacen referencia a actividades planificadas por las instituciones llegan a las redacciones de los medios de comunicación en forma de notas y convocatorias de prensa, que son reproducidas o interpretadas por los medios repetidamente. En menor medida, dan cuenta de actividades extraordinarias protagonizadas por un menor, subrayándose la superación en alguna disciplina. El interés informativo suele darse en razón de las características o edad de los niños y niñas, y aunque el enfoque, muy positivo, subraya sus capacidades y su esfuerzo, conviene equilibrar lo positivo que resulta mostrarlos como parte de la realidad social de interés con el riesgo de presentarlos como atracciones.

\subsection{Educación}

Las piezas informativas centradas en el ámbito educativo son, con diferencia, las que mayor presencia alcanzan en el conjunto de las observadas: suponen el $27 \%$ del total. Los y las menores son protagonistas indirectos de una gran parte de las informaciones publicadas, en tanto que objetos pasivos y destinatarios de un sistema educativo que alcanza notoriedad informativa en muchas ocasiones, pero respecto al cual los niños y niñas poco o nada tienen que decir. 
No es desdeñable el número de piezas centradas en dar cuenta del rendimiento académico de los menores vascos o españoles, informando de sus resultados en distintas pruebas comparativas que analizan el grado de aprovechamiento de los recursos educativos, el nivel de competencias adquiridas o los esfuerzos del engranaje institucional por escolarizar a la población infantil y adolescente. Se difunden, por ejemplo, informaciones basadas en informes como el PISA. También se publican piezas que aluden a la bajada de los resultados académicos o de la excelencia en la educación. Si bien estas piezas se apoyan en parámetros objetivables, suelen percibirse interpretaciones intencionadas de las mismas, básicamente dirigidas a justificar o promover modificaciones en el sistema educativo y, en particular, de la Enseñanza Secundaria Obligatoria. Este marco interpretativo está relacionado con el cuestionamiento de los gobiernos encargados del desarrollo o impulso del sistema educativo, que se hace particularmente evidente en las interpretaciones marcadamente negativas del estado de la educación en Euskadi. Titulares como "Einstein no estudia en Euskadi" (Diario Vasco, 12/12/2010) o "La educación vasca, la más cara pero entre las peores" (El Mundo, 20/4/2010) ilustran esta tendencia.

La educación constituye un ámbito problemático en tanto que en él confluyen intereses de varios tipos: políticos, ideológicos, económicos e incluso religiosos. La prensa mira a la escuela y la retrata entendiendo que mantener un sistema educativo adecuado a las expectativas y necesidades es fundamental. Sin embargo, cuando los periódicos se refieren a la educación describen un escenario para el enfrentamiento: hablan sobre todo de decisiones políticas al respecto a la planificación del sistema educativo. Y lo hacen sin mencionar en la mayor parte de los casos a sus usuarios más directos: niños y niñas suelen ocupar un papel marginal en muchas de las informaciones directamente relacionadas con ellos. Los menores no pueden ser los responsables del diseño de los planes educativos. Pero en la mayoría de las piezas que abordan algún aspecto relacionado con la educación no hay referencias directas y expresas a ellos ni al profesorado: las voces sobre la educación en los medios están prácticamente copadas por representantes de partidos políticos. La presencia de los menores se limita prácticamente al análisis y fiscalización de sus resultados académicos, desde perspectivas bastante sesgadas que ponen el acento únicamente en las vertientes negativas de los resultados del alumnado, que suelen pasar por alto, como necesario contexto, algunos datos relevantes del sistema educativa español, como la menor inversión pública en educación respecto a otros países del entorno.

\subsection{Infancia, familia y sociedad}

En términos cuantitativos, esta área es la segunda más extensa, habiéndose incluido bajo su amplio y heterogéneo paraguas un total de 93 piezas -el 11\% del total-. Con respecto a los subtemas, las noticias relacionadas con el reparto de tareas domésticas y conciliación laboral son las que aparecen con mayor frecuencia: una de cada tres noticias relacionadas con este epígrafe y la familia en general (34\%) corresponden a piezas que abordan la necesidad de medidas que faciliten a padres y madres sus respectivos desarrollos profesionales con la crianza de unos niños y niñas. El segundo epígrafe en cuanto a volumen de piezas engloba una serie de cuestiones variadas, el 
tercero hace lo propio con noticias y reportajes relacionados con la adopción o la acogida de menores y las legislaciones al respecto, y el cuarto alude a piezas relacionadas con las separaciones y la tutela de los y las menores, así como con la revisión de la posibilidad de establecer custodia compartida o de negársela a los hombres implicados en casos de maltrato a sus esposas. Todas estas cuestiones abordan de uno u otro modo la regulación de la convivencia doméstica y el lugar que los menores ocupan dentro del seno de sus familias, dándose por hecho en todo momento que la infancia es un sector a proteger. Y que exige la responsabilidad, tiempo y recursos tanto de sus familias como de las instituciones que, en su caso, han de velar por ellos. La mayoría de las piezas recogidas dentro de esta temática tienen su origen en la $\mathrm{CAV}$, lo cual certifica la cercanía con la que se abordan estas cuestiones.

El enfoque siempre sugiere la necesidad de que las condiciones de conciliación mejoren y que los hombres se comprometan en mayor proporción e intensidad tanto con las tareas domésticas como con el cuidado de sus hijos e hijas. También es reseñable la perspectiva, siempre en positivo, con la que se abordan las informaciones relacionadas con menores extranjeros que pasan el verano con familias vascas ${ }^{9}$-: la prensa recoge con claridad que las familias consideran la experiencia positiva tanto para los visitantes como para ellas mismas.

Sin embargo, las noticias referidas a instituciones de acogida reciben un enfoque totalmente diferente. Estas piezas se centran habitualmente en la presunta actividad delictiva de quienes se encuentran internados en ellos y en los problemas para la sociedad que acarrean sus actividades. Los y las menores atendidos en estos centros parecen estar situados al margen de la sociedad, y son sujetos noticiosos únicamente en razón de aspectos negativos que están relacionados tanto con polémicas institucionales como con actos delictivos atribuidos. Resulta preocupante que no aparezcan reflejados en la prensa con más frecuencia aspectos relacionados con la integración de los y las menores problemáticos o enfoques que presenten en positivo la labor que desempeñan las instituciones, y no tanto que evidencien casos de fracaso. Como consecuencia de ello, es más difícil transmitir a la opinión pública los esfuerzos realizados por asistir, atender y educar a los y las menores en situación más precaria.

\subsection{Menores como víctimas}

En general, los y las menores son retratados en una situación de indefensión por la prensa. A este respecto, se han distinguido nueve subtemas dentro de este apartado, que agrupa a una de cada cinco piezas analizadas $(20 \%, 169)$. Cabe destacar, en primer lugar, que del conjunto de las piezas consideradas dentro de este apartado el $26 \%$ versan sobre abusos sexuales en general, a los que añadir las que se refieren a abusos sexuales cometidos en el seno de la Iglesia católica $(16 \%)$ y los que se producen dentro del entorno familiar (1\%). Las noticias también reflejan que niños y niñas sufren en sus propias carnes la violencia que generan las guerras y los desastres naturales (9\%) $y$ en ocasiones la violencia que se genera en sus propios hogares (12\%). Los menores

9 En Euskadi está bastante asentada la acogida temporal de niños y niñas procedentes de Sáhara y de Chernobil. 
aparecen pueden aparecer como víctimas de accidentes (13\%) y de la pobreza (10\%). Las piezas periodísticas que los relacionan con desastres naturales y guerras se refieren siempre al ámbito internacional, y de manera específica aparecen repetidas referencias relacionadas con las consecuencias del terremoto que sacudió Haití el 12 de enero de 2010 y cuyas consecuencias son abordadas por la prensa a lo largo del año.

Comprobamos, por tanto, que la prensa contempla la figura del menor como víctima desde diferentes perspectivas. A nivel general, la infancia es retratada como un sector particularmente indefenso y vulnerable. Cuando los menores son víctimas de agresiones, violencia, conflictos bélicos o desastres naturales, la prensa suele incidir en ello, contribuyendo a representar y exacerbar lo dramático de las situaciones en las que están involucrados. La infancia, por tanto, actúa como un poderoso reclamo para sensibilizar al público: son empleados como catalizadores para promover a la solidaridad o la empatía del público. Este recurso debería emplearse con cierta cautela: las imágenes que muestran a niños y niñas de países en desarrollo sufriendo suelen presentarlos sin preservar su intimidad.

No obstante, la prensa también refleja y potencia una creciente sensibilidad social respecto a la pornografía infantil y los escándalos sexuales, incluidos los que implican a sacerdotes católicos, contribuyendo a visibilizar la cuestión.

\subsection{Menores con conductas violentas}

Las informaciones y piezas de opinión centradas en la violencia que generan o pueden generar los menores tiene una presencia limitada $(3 \%, 18$ piezas ) que, no obstante, subraya y alimenta algunas de las connotaciones negativas asociadas a la imagen del colectivo. Se han identificado cuatro subtemas para distinguir los modos en los que la prensa refleja las conductas violentas generadas por chicos y chicas: casos de agresión protagonizados los menores a título individual (52\%); conductas violentas dentro de bandas o colectivos organizados que suponen el (11\%); intimidación que desde casa realizan hacia otros miembros de la propia familia (19\%); y bajo el epígrafe otros $(18 \%)$ el resto de noticias referidas a la conducta más agresiva de niños y niñas.

Aunque en términos absolutos el número de piezas publicadas respecto a estas cuestiones es limitado y dificulta la extracción de conclusiones sólidas, es indiscutible que de su análisis se deduce que la violencia que ejercen menores en el seno de la familia recibe prioritaria atención mediática, y es objeto de enfoques dramáticos, espectaculares y poco afortunados. Ejemplo de ello pueden ser titulares como "Socorro, mi hijo me mata" (El Mundo, 13/02/2010) o "Gótica, especial, maja, cubanita y sádica" (El Mundo, 11/04/2010) ${ }^{10}$.

Si bien la prensa no refleja muchas informaciones sobre comportamiento violento protagonizado por menores, la aplicación de la escala de atención indica que ese tipo de piezas suelen ser consideradas altamente importantes, y el análisis de contenido nos permite hablar, en ocasiones, de un tratamiento marcadamente sensacionalista. La cobertura periodística basada en el morbo, la reconstrucción o la exhaustividad no parece la mejor manera de generar una conciencia social honesta y certera respecto a

${ }^{10}$ En referencia a la niña de Seseña que supuestamente asesinó a una compañera de clase. 
la cuestión. La desaparición de Marta del Castillo -enero de 2009- o el asesinato de Seseña -abril 2010-, en los que tanto las víctimas como los presuntos victimarios eran menores de edad, suelen irrumpir en las agendas de los medios, que los abordan a caballo entre el interés periodístico, la irresponsabilidad y la generación de alarma.

\subsection{Menores y nuevas tecnologías}

Todas las cabeceras analizadas incluyen noticias a este respecto ( $2 \%, 18$ piezas), lo que certifica la importancia que se otorga al modo de relacionarse con las nuevas tecnologías de los menores. De su análisis cualitativo se deduce que cuando hablan de esta cuestión los medios subrayan en particular los sucesos derivados del mal uso de ellas. En algunos casos puntuales, ese mal uso se llega a generalizar, vinculándose de modo directo las nuevas tecnologías y la violencia: "La generación de los cibermatones", titula Deia $(11 / 4 / 2010)$.

La prensa ayuda a conducir la percepción de los adultos con respecto a la relación de los y las menores y las nuevas tecnologías, ahondando en el mito del supuesto dominio de los adolescentes en este ámbito. Este extremo es difícil de comprobar y alimenta, sin embargo, la imagen del colectivo adolescente como endogámico y con dificultades para comunicarse con su familia. A su vez, resulta llamativa la frecuencia con la que internet es retratado como una herramienta de acoso y violencia. La actividad periodística debería dar cuenta de usuarios adolescentes que no descuidan el resto de facetas de sus vidas al margen de las nuevas tecnologías, y no dar por sentado el analfabetismo digital de la población adulta, evitando apuntalar tópicos perjudiciales para el entendimiento entre los y las menores y el resto de la sociedad.

\subsection{Menores y salud}

La información periodística sobre salud ocupa cada vez más espacio en la prensa escrita $(8 \%, 66$ piezas). Incluso algunos medios han contado o cuentan con secciones o cuadernillos dedicados a esta temática. En los periódicos vascos encontramos cinco subtemas que relacionan directamente infancia y adolescencia y salud: aspectos relacionados con la salud en general (49\%); atención médico-sanitaria destinada a la infancia (16\%); piezas en las que hay alusiones a menores y tabaco, alcohol y otras drogas (12\%); y cuestiones relacionadas con la alimentación (11\%). El 12\% de las piezas restante aborda cuestiones relacionadas con menores y salud dentro de otros enfoques no especificados.

Al profundizar en el análisis de estas informaciones encontramos que la mayoría de ellas hacen referencia y están relacionadas con la Comunidad Autónoma Vasca y abordan la infancia de un modo general. Aun así, cabe destacar la atención que reciben cuestiones relacionadas con la cobertura sanitaria destinada a niños y niñas en el ámbito internacional, especialmente en lo referido a guerras y desastres. A su vez, en algunas piezas informativas, además, se mencionan casos concretos de menores que se convierten en noticia en virtud de intervenciones o tratamientos médicos a los que tienen que ser sometidos. En estas informaciones se suele destacar la fortaleza con la que los niños y niñas hacen frente a la situación y a su capacidad de superación. Ejemplo de ello son reportajes el que retrata a un grupo de menores que han recibido im- 
plantes de brazo (El Correo, 21/2/2010) o el que relata la vivencia de un niño con atrofia muscular espinal que está obligado a utilizar una silla de ruedas (El Pais, 12/1/2010), destacándose en estos casos valores positivos como la capacidad de superación. Al igual que en las piezas referidas a desastres humanitarios o violentos que implican a menores incrementan el dramatismo del relato, las enfermedades graves padecidas por niños y niñas presentan a éstos como víctimas de circunstancias doblemente crueles. Las noticias sobre salud, investigación médica o avances científicos relacionados con la infancia, cuidando no caer en la presentación morbosa de elementos testimoniales, contribuyen a sensibilizar respecto a esta área.

\section{Conclusiones}

La infancia y la adolescencia ocupan un lugar importante dentro de la agenda de los medios: en todos los periódicos se han identificado un buen número de piezas de temáticas que están relacionadas de un modo u otro con los y las menores. Asimismo, y aunque hayan quedado al margen del estudio, también hay que considerar que algunos diarios dedican a la infancia o sus actividades suplementos específicos de carácter regular.

La edad del o la protagonista constituye un factor importante al analizar las piezas relacionadas con este colectivo heterogéneo. En general, la mayoría de las cuestiones negativas, fundamentalmente relacionadas con conductas violentas, pero también la pasividad o falta de iniciativa están ligadas a menores de entre 12 y 15 años, y a adolescentes en general. Por el contrario, las informaciones relacionadas con niños o niñas más pequeños, o incluso con la maternidad, aparecen vinculadas a aspectos positivos. Así, la noticiabilidad basada en la desviación negativa es más evidente a medida que la edad de los sujetos avanza. Este marco interpretativo coincide con la irrupción de varios programas televisivos que han utilizado la imagen del adolescente -no forzosamente menor- como protagonista de realities televisivos.

Aunque hay algunas piezas que denuncian situaciones de sexismo vivido por niñas en diferentes puntos del planeta, en un ámbito más cercano se detecta en muchas ocasiones que el uso de lenguaje no sexista sigue siendo una asignatura pendiente. Los periódicos suelen hacer referencia a colectivos de los que participan hombres y mujeres, en nuestro caso niños y niñas, empleando plurales masculinos falsamente universales que contribuyen a invisibilizar a las alumnas, o las chicas que hacen deporte escolar. La economía de palabras debería hacerse compatible con expresiones que realmente integren al colectivo femenino: es papel de los medios hacer un esfuerzo por implementar buenas prácticas comunicativas.

La necesidad de una especial sensibilidad por parte de la prensa al abordar la realidad informativa de los menores constituye una evidencia, que de hecho, y así lo recogen numerosos pronunciamientos, informes y libros de estilo. Pero, como se ha expuesto, las menciones relativas a la infancia suelen limitarse al empleo y manipulación de la imagen, y no llegan a indicar de modo expreso qué marcos interpretativos deberían prevalecer al informar al respecto. Aunque los y las periodistas den por sabido que al abordar estas informaciones hay que hacerlo con sensibilidad y sentido común. 
La ausencia de una normativa concreta en referencia a la presencia de los menores en los medios de comunicación o en los propios mecanismos de autorregulación de los medios nos lleva a referirnos, de nuevo, a las indicaciones realizadas por la FIP anteriormente descritas. Y aunque a nivel general, y tras la observación práctica y el trabajo de campo cabe deducir que la mayoría de las sugerencias de la FIP son generalmente respetadas, hay dos recomendaciones que deberían subrayarse con atención.

En primer lugar, la referida a la conveniencia de evitar el uso de estereotipos y la presentación sensacionalista para promover material periodístico que implique a niños y niñas. En este sentido, la tendencia de la prensa a emplear un tratamiento más sensacionalista de las noticias y la espectacularización de las mismas ha sido ampliamente documentada en diversos trabajos, de ámbito tanto estatal como internacional. La presión por la búsqueda de audiencias, el reto que implica para la prensa escrita la competencia con la visualidad de la televisión y la inmediatez de Internet, y una precarización de las condiciones laborales de los profesionales de la información son algunos de los motivos que explican esta tendencia. Su consecuencia más evidente es un deterioro de la calidad de la información y por tanto empobrecimiento del debate social y político así como un desplazamiento de la agenda a temas de menor relevancia social. Y si esto es así con respecto al conjunto de las informaciones, en algunas de las piezas relacionadas con menores analizadas se observa un tratamiento que puede ser calificado de sensacionalista y que en ocasiones puede tener como consecuencia la creación de estereotipos negativos para la infancia. Es el caso especialmente de las piezas vinculadas con la violencia de menores o, como se ha indicado previamente, la educación.

Por otra parte la FIP sugería que, siempre que fuese posible, se diese a niños y niñas el derecho a acceder a los medios de comunicación para expresar sus propias opiniones sin alicientes de ningún tipo. $Y$ tal y como se pone de manifiesto en las conclusiones del trabajo, los y las menores apenas aparecen como agentes activos en las noticias que hablan sobre ellos cuando sus aportaciones probablemente complementarían el punto de vista con respecto al colectivo que la prensa contribuye a elaborar y difundir.

\section{Referencias bibliográficas}

AIMC (2012): Marco General de los medios en España 2012: http://www.aimc.es/Marco-General-.html [fecha de consulta: 5 de marzo de 2012]

ARIAS, Marta; BELLO, Armando; VON BREDOW, María; y GONZÁLEZ-BUENO, Gabriel (2010): La infancia en España 2010-2011. 20 años de la Convención sobre los derechos del Niño: retos pendientes. Madrid, UNICEF España.

ARMENTIA, José Ignacio y CAMINOS, José Ma (2009): Redacción Informativa en Prensa. Barcelona, Ariel Comunicación.

AFIN (2009): “La infancia en los medios de comunicación". Newsletter, mayo, 2009: http://uab.academia.edu/AFINBarcelona/Papers/1294486/Newsletter_N_3_Mayo_ de_2009_ADOPCIONES_FAMILIAS_INFANCIAS_La_infancia_en_los_medios_de_comunicacion [fecha de consulta: 5 de marzo de 2012 ] 
ALCOCEBA, José Antonio y MATHEUS, Gladys (2010): "El discurso mediático sobre los jóvenes en España". Anuario Electrónico de Estudios en Comunicación Social Disertaciones, vol. 3 (1): http://erevistas.saber.ula.ve/index.php/Disertaciones/article/view/695/650 [fecha de consulta: 6 de marzo de 2012]

ALZATE, Ma Victoria (2001): "Concepciones e imágenes de la infancia”. Revista de Ciencias Humanas, 28. Universidad Tecnológica de Pereira. Colombia: http://www.utp.edu.co/ chumanas/revistas/revistas/rev28/alzate.htm (fecha de consulta: 5 de marzo de 2012).

BERRIA (2006): Estilo liburua. Andoain, Berria.

BUDD, Richard (1964): “Attention score: An advice for measuring news play”. Journalism Quaterly, 41.

CASAS, Ferrán (1998): Infancia: perspectivas psicosociales. Barcelona, Paidós Ibérica.

CASAS, Ferrán (2006): "Infancia y representaciones sociales", Política y Sociedad, Vol. 43 (1).

EL MUNDO (1996): Libro de Estilo. Madrid, Unidad Editorial.

EL PAÍS (2002): Libro de estilo. Madrid, Santillana.

ENTMAN, Robert (1993): "Framing: toward clarification of a fractured paradigm", Journal of Communication, 43 (4), pp. 51-58.

GARCÍA, Emilio; CARRANZA, Elías (1999): "El derecho de "menores" como derecho mayor". En El derecho a tener. Instituto Interamericano del Niño, la Niña y Adolescentes, http://iin.oea.org/El_derecho_de_menores.pdf [fecha de consulta: 21 de febrero de 2012]

GARCÍA, Isabel (2011): "Autorregulación o normativa", en Menores en los medios de comunicación. Madrid, Defensor del Menor de la Comunidad de Madrid, Consejo general de la Abogacía Española, Asociación de la Prensa de Madrid.

GARMENDIA, Maialen; GARITAONANDIA, Carmelo; MARTÍNEZ, Gemma; y CASADO, Miguel Ángel (2012): "Los menores españoles en la red. Usos y riesgos desde una perspectiva europea", Quaderns del CAC, 38.

GIRÓ, Xavier (2003): "La imatge de la joventut a la premsa. Valors, política i violència”. En Anàlisi, 30, pp. 105-124.

IGARTUA, Juan José y HUMANES, $\mathrm{M}^{\mathrm{a}}$ Luisa (2004): Teoría e investigación en comunicación social. Madrid, Síntesis.

IGARTUA, Juan José; MUÑIZ, Carlos; y OTERO, José Antonio (2006): "El tratamiento informativo de la inmigración en la prensa y la televisión española. Una aproximación empírica desde la teoría del Framing". Global Media Journal, vol.3, 5, http://gmje.mty.itesm.mx/igartua_muniz_otero.htm [fecha de consulta: 4 de marzo de 2012]

MARTÍNEZ DE SOUSA, José (2003): Libro de Estilo Vocento. Gijón, Ediciones Trea. 
PÉREZ OLIVA, Milagros (2010): "Criterios para el tratamiento de las imágenes de menores", en El Pais, 12 de julio, http://blogs.elpais.com/defensora-del-lector/2010/07/criterios-para-el-tratamiento-de-las-im\%C3\%A1 genes-de-menores.html [fecha de consulta: 21 de febrero de 2012]

PONTE, Cristina; BAUWENS, Renate Jo; MASCHERONI, Giovanna (2009): "Children and the internet in the news: agency, voices and agendas", en LIVINGSTONE, S., and HADDON, L. (eds): Kids online. Opportunities and risks for children. Bristol, The Policy Press.

SÁDABA, Teresa (2001): “Origen, aplicación y límites de la «teoría del encuadre» (framing) en comunicación”. Comunicación y Sociedad, vol. XIV (2), pp. 143175.

TUCHMAN, Gaye (1983): La producción de la noticia. México, Gustavo Gili.

WHITE, Aidan (2002): Restituir los derechos de la infancia. Guía para periodistas y profesionales de la prensa. Bruselas, FIP: http://www.unicef.org/lac/restituirlos derechosdelainfanciaguiaparaperiodistas.pdf) [fecha de consulta, 21 de febrero de 2012]

WIMMER, Roger D. y DOMINICK, Joseph R. (1996): La investigación cientifica de los medios de comunicación. Una introducción a sus métodos. Barcelona, Bosch Comunicación. 